\title{
Isolation of Burkholderia cepacia JBK9 with plant growth- promoting activity while producing pyrrolnitrin antagonistic to plant fungal diseases
}

\author{
Byung Kwon Jung ${ }^{1}$ Sung-Jun Hong ${ }^{1}$ Gun-Seok Park ${ }^{2}$ • \\ Min-Chul Kim ${ }^{1} \cdot$ Jae-Ho Shin ${ }^{1,3}$ (1)
}

Received: 18 November 2017/Accepted: 3 January 2018/Published online: 3 February 2018

(C) The Korean Society for Applied Biological Chemistry 2018

\begin{abstract}
Burkholderia species are widely distributed across wide ecological niches. Many genera of Burkholderia are known to be associated with plants and are involved in processes such as suppression of soil-borne pathogens, acceleration of plant growth and endophytic colonization. In the present study, a strain belonging to the Burkholderia cepacia complex, which was termed JBK9, was isolated. The strain JBK9 showed broad-spectrum antifungal activities against Phytophthora capsici, Fusarium oxysporum, and Rhizoctonia solani, which are representative phytopathogenic fungi, inhibiting their growth by $59.56,51.92$, and $34.22 \%$, respectively. The strain produced an antifungal compound that was confirmed to be pyrrolnitrin by TLC, HPLC, and NMR analyses. Using an in vitro assay for plant root colonization, we observed that the population densities of B. cepacia JBK9 on the upper $1 \mathrm{~cm}$ of host plant roots were significantly different between Burkholderia species. The high motility of these strains is likely to have contributed to their efficient root colonization. The isolated strain was evaluated in vivo for its ability to control Phytophthora blight via a pot test. Compared with Burkholderia strains KCTC 2973 and
\end{abstract}

Byung Kwon Jung and Sung-Jun Hong have contributed equally to this work.

Jae-Ho Shin

jhshin@knu.ac.kr

1 School of Applied Biosciences, College of Agriculture and Life Sciences, Kyungpook National University, 80 Daehakro, Buk-gu, Daegu 41566, Republic of Korea

2 Department of Biomedical Engineering, The University of Texas at Austin, Austin, TX 78712, USA

3 Institute of Agricultural Science and Technology, Kyungpook National University, Daegu 41566, Republic of Korea
ATCC 25416, B. cepacia JBK9 demonstrated a stronger antifungal activity against $P$. capsici. The strain $B$. cepacia JBK9 could be further developed as a biological control agent for pepper plants.

Keywords Antifungal activity - Biological control · Burkholderia cepacia $\cdot$ Pyrrolnitrin

\section{Introduction}

Various phytopathogenic fungi such as Phytophthora capsici and Fusarium oxysporum are existed in soil [1]. Among them, P. capsici causes rotting in the roots and fruits of commercially important crops [2]. In general, farmers have been in trouble to control plant diseases caused by Phytophthora species because of their resistance to metalaxyl, a systemic fungicidal compound that is effective against most oomycetes. Generally, wide range of chemical fungicides are needed to manage $P$. capsici which has a broad host range [3]. But, such chemicals can also eliminate soil insects and microorganisms that are beneficial for the rhizosphere. In addition, the excessive use of chemicals to control $P$. capsici has affected human health concerns, as well as the development of tolerance to target microbial populations [4].

Biological control is an alternative method to replace chemical fungicides. Many bacterial agents have been discovered via in vitro or in vivo screening of large numbers of microorganisms that inhibit plant pathogens [5]. Potential bacterial antagonists that have been discovered using this strategy include B. cepacia [6], Pseudomonas spp. [7], and Bacillus spp. [8]. Nevertheless, potential biological control agents discovered using this method 
must be subjected to further screening by repeating analyses, which is laborious and requires facilities with controlled environmental conditions. Therefore, an effective screening strategy should begin with a fast and simple in vitro or in vivo analysis of antagonistic action [5].

The genus Burkholderia is an organism with remarkable production of various secondary metabolites [9], including many compounds with antibacterial, antifungal, insecticidal, or herbicidal properties [10]. Burkholderia cepacia complex (BCC) is known to produce pyrrolnitrin and cepacin, natural substances with antimicrobial activity.

Pyrrolnitrin is a potent antimicrobial material produced by Burkholderia, Pseudomonas, Myxococcus, Serratia, and Enterobacter genera. BCCs protect themselves by this substance against phytopathogenic fungi such as Rhizoctonia solani, $P$. capsici, and $F$. oxysporum [7, 11]. Several Burkholderia species have been suggested as effective biocontrol agents, and some of their metabolites are developed to commercial products. In this study, we focused on isolating a bacterial strain for the effective biocontrol of plant pathogens and investigated its practical application in pepper plants via a pot experiment.

\section{Materials and methods}

\section{Screening of antagonistic bacteria from soil}

A total of 25 soil samples were collected from 25 different locations in Gyeongsangbuk-do area, Republic of Korea for bacterial screening. The upper soil layer samples (approximately $100 \mathrm{~g}$ ) were placed into clean dry and sterile polythene bags. The sample was suspended in $0.85 \%$ of $\mathrm{NaCl}$ and spread on Luria-Bertani (LB) agar. After incubation for 2 days at $30{ }^{\circ} \mathrm{C}$, bacterial colonies with different morphological characteristics were selected and restreaked on fresh LB agar until the homogeneous colonies were appeared. Isolated strains were subcultured in LB broth on a rotary shaker. For long-term storage of the strain, $50 \%(\mathrm{v} / \mathrm{v})$ glycerol solution was added to culture and freezed at $-80{ }^{\circ} \mathrm{C}$ until use.

Fungal strains used in the present study include, Rhizoctonia solani KACC 40101, Fusarium oxysporum KACC 40032, Phytophthora capsici KACC 40476, and Corynespora cassiicola KACC 40964 were obtained from the Korean Agricultural Culture Collection. The antifungal activity of each isolated strain was determined by the grow inhibition of pathogenic fungi. Test was performed with three replicates. The growth rate of pathogenic fungi was assessed using the modified method by Reyes-Chilpa et al. [12]. Antagonistic activity was defined according to the size of the inhibitory zone after 1 week as follows: +++++ (very strong), > $20 \mathrm{~mm}$; ++++ (strong),
$>15-20 \mathrm{~mm} ;+++$ (moderate), $>10-15 \mathrm{~mm}$; + (very weak), $0-5 \mathrm{~mm}$; ++ (weak), $>5-10 \mathrm{~mm}$; - no inhibition zone.

\section{Identification of isolated strain and phylogenetic analysis}

Each isolate was identified by $16 \mathrm{~S}$ rRNA gene sequencing and comparison according to the methods of Mejri et al. [13]. PCR amplification was performed with $K O D$ DNA polymerase using the universal primer set $27 \mathrm{~F}\left(5^{\prime}\right.$ GAGAGTTTGATCCTGGCTCAG) and 1492R (5'CTACGGCTACCTTGTTACGA). The 16S rRNA gene fragments were purified using PCR purification kit (Enzynomics, Daejeon, Korea). DNA sequencing was conducted SolGent (Daejeon, Korea). The sequences were analyzed using the EzTaxon-e database for species identification [14]. The phylogenetic analysis was done using the neighbor-joining algorithm and the $p$-distance model in MEGA version 6.0 [15].

\section{Scanning electron microscopy}

To obtain SEM image, a $1-\mathrm{cm}^{2}$ transverse section of bacterial strain on LB agar plate was obtained and fixed in $2.5 \%$ glutaraldehyde buffer for $3 \mathrm{~h}$ at $4{ }^{\circ} \mathrm{C}$. The cell was washed and then fixed for $1 \mathrm{~h}$ at $25^{\circ} \mathrm{C}$ in $1 \%$ osmium tetroxide. After washing, the cell was dehydrated with $50-100 \%$ of graded series of ethanol, dried critical point, and platinum-coated using an ion-sputter coater. The specimen was observed at an operating voltage of $2 \mathrm{kV}$ using a field-emission scanning electron microscopy/energy-dispersive X-ray spectrometry microscope (model S-4100, Hitachi, Tokyo, Japan).

\section{Motility (swarming and swimming) evaluation}

To measure motility of the cell, $10-\mu \mathrm{L}$ overnight culture broth of bacteria was spotted onto swarming agar plate ( $0.4 \%$ glucose in LB broth and $0.45 \%$ agar) and/or swimming agar plate ( $1 \%$ tryptone, $0.5 \% \mathrm{NaCl}$, and $0.3 \%$ agar) and incubated for $24 \mathrm{~h} \mathrm{[16].} \mathrm{Swarming} \mathrm{and} \mathrm{swimming} \mathrm{agar}$ plates were dried for overnight at $25{ }^{\circ} \mathrm{C}$ and preheated to $30{ }^{\circ} \mathrm{C}$ before use.

\section{Rhizosphere colonization using a double-layered filter paper method}

This experiment followed the protocol of Bae et al. [17]. Surface of red pepper seeds were disinfected by treatment of $1 \%$ sodium hypochlorite for $5 \mathrm{~min}$. After treatment, the seeds were carefully washed with sterile water, and dried. One gram of red pepper seeds were treated with $10^{9}$ 
Colony Forming Unit (CFU) of bacterial solution $\left(10^{9} \mathrm{CFU}\right.$ $/ \mathrm{mL}$ ) and air-dried for $1 \mathrm{~h}$. Then, two sheets of Whatman No. 1 filter paper (Whatman, UK) were placed on the $11-\mathrm{cm}$ Petri dish and soaked in $5 \mathrm{~mL}$ of sterile water. After the filter paper had absorbed the water uniformly, 10 seeds coated with bacteria (B. cepacia JBK9, B. pyrrocinia KCTC 2973, and B. cepacia ATCC 25416) were placed vertically, seed side up, between the filter paper sheets on the far side of a Petri dish. This allowed the root to grow downwards across the Petri dish. The lid was covered and sealed with paraffin film and the Petri dish was incubated at $30{ }^{\circ} \mathrm{C}$ without light for 7 days. After incubation, the roots were taken from each Petri dish and cut into $1-\mathrm{cm}$ segments. The quantity of each bacterial strain $(\mathrm{CFU} / \mathrm{mL}$ ) on the rhizoplane of each root segment was determined by plating the root segments on LB medium.

\section{Biocontrol of $P$. capsici by B. cepacia JBK9}

For the pot trial, V8 juice agar medium (10\% V8 juice, $0.1 \% \mathrm{CaCO}_{3}$, and $2 \%$ agar) was used for to prepare zoospores of $P$. capsici. The fungus inoculated agar plate was incubated for 5 days at $30{ }^{\circ} \mathrm{C}$ under the fluorescent light to produce sporangia. Chilling at $4{ }^{\circ} \mathrm{C}$ for $0.5 \mathrm{~h}$ was done to release zoospores. Sterilized water suspension of the zoospore was carefully filtered by cheesecloth. The final concentration of the zoospore was $10^{5}$ zoospores $\mathrm{mL}^{-1}$ [18]. Pepper seeds (Capsicum annuиm L., Chungok) were planted on the soft seeding soil. Sprouted pepper were implanted to artificial sterile soil (soil/sand/vermiculite, 2:1:1, v:v:v) and then cultivated at $25{ }^{\circ} \mathrm{C}$ with 16 -h period $10,0001 \times$ of light. After 6 weeks of transplanting, $5 \mathrm{~mL}$ of a zoospore suspension of $P$. capsici $\left(10^{5}\right.$ zoospores $\left./ \mathrm{mL}\right)$ was poured into the pot for the infected samples. For the bacterial treated samples, $50 \mathrm{~mL}$ of each culture broth $\left(10^{9}\right.$ $\mathrm{CFU} / \mathrm{mL}$ ) was applied during the day. The same volume of sterile medium was used as a control. Pepper plants and rhizospheric soils were collected after 20 days of treatment.

\section{Extraction of antifungal compound from B. cepacia JBK9}

In order to extract the antifungal compound, the culture broth of strain JBK9 was centrifuged at $10,000 \times g$ for $20 \mathrm{~min}$. The supernatant was carefully corrected and filtered to remove any bacterial cells using a $0.2-\mu \mathrm{m}$ cellulose acetate filter. The filtered culture was mixed 1:1 (v/v) with $n$-hexane. The organic phase was evaporated under vacuum at $40{ }^{\circ} \mathrm{C}$ using a rotary evaporator (Sunil Eyela, Seongnam, Korea). The dry residues were resuspended in $1 \mathrm{~mL}$ of $100 \%$ methanol. Extracts were stored in microtubes at $-20{ }^{\circ} \mathrm{C}$ until use.

\section{Thin-layer chromatography (TLC) assay}

TLC was performed to fractionate compounds from secondary metabolic extracts of B. cepacia JBK9. A TLC silica gel 60 F254 plate (Millipore, Billerica, MA) with dimensions of $20 \times 20 \mathrm{~cm}$ was used. Secondary metabolite extracts were spotted on a $2 \mathrm{~cm}$ TLC plate from the base at least $2 \mathrm{~cm}$ away across the horizontal baseline. The plates were developed vertically in a glass chromatography tank containing $100 \mathrm{~mL}$ of solvent $(3: 1[\mathrm{v} / \mathrm{v}] n$-hexane/ethyl acetate) until the solvent tip reached $1 \mathrm{~cm}$ from the top edge of the TLC plate. Samples were visualized using ultraviolet radiation at two wavelengths (256 and $354 \mathrm{~nm}$ ). Pure pyrrolnitrin (3-chloro-4-[3-chloro-2-nitrophenyl]pyrrole; Sigma-Aldrich, St. Louis, MO) was used as a compound of positive reference for the newly isolated active compounds.

\section{Reverse-phase HPLC and NMR analyses}

The bioactive fraction was further purified by HPLC. A $\mathrm{C}_{18}$ column (Phenomenex, Torrance, CA) was used with following HPLC instrumental conditions: (1) CBM-10 system controller coupled with an ultraviolet-visible detector set at $225 \mathrm{~nm}$ and an LC-10AD pump; (2) Solvent A, 45\% $\mathrm{H}_{2} \mathrm{O}$, $30 \%$ acetonitrile, $25 \%$ methanol; (3) $1 \mathrm{~min} / \mathrm{mL}$ flow rate for $30 \mathrm{~min}$. The pyrrolnitrin (Sigma-Aldrich) was used as a standard. The NMR spectrum of pyrrolnitrin was obtained using a Bruker's NMR machine (Advance Digital, Bruker, Billerica, MA) operating at $500 \mathrm{MHz}\left({ }^{1} \mathrm{H},{ }^{13} \mathrm{C}\right)$.

\section{Results}

\section{Isolation of strain JBK9}

We collected 25 soil samples (100 g, each) from the rhizosphere of cultivated crops in Gyeongsangbuk-do, Republic of Korea. Bacteria were obtained both from rhizospheric portion of various plants. A total of 115 microorganism strains were isolated from rhizospheres of several agricultural crop fields. The antagonistic activities of those microorganisms against fungal pathogens were assessed by the dual-culture method. A total of 150 isolates that appeared as separate colonies were isolated from soil rhizosphere where sampled from Gyeongsanbuk-do area. All isolated bacteria were tested for antifungal activity as follows: a $1 \mathrm{~cm}^{2}$ fungal plug was inoculated in the center of a plate with PDA; each isolated bacterium was sown with a sterile stick at a distance of $2.5 \mathrm{~cm}$ from the fungi. The isolate named JBK9 showed antagonistic activity against $R$. solani, $P$. capsici, and $F$. oxysporum. When strain JBK9 was inoculated with each of the three fungal 
pathogens and cultivated for 7 days, it inhibited the growth of $P$. capsici, F. oxysporum, and $R$. solani by $59.56,51.92$, and $34.22 \%$, respectively (Table 1 ).

\section{Morphology and identification of the strain JBK9}

Strain JBK9 was a gram-negative and rod-shaped bacterium (Fig. 1A). The 16S rRNA gene region (1421 bp) was amplified by the universal primers $27 \mathrm{~F}$ and $1492 \mathrm{R}$. After sequencing, the sequence was aligned against other sequences used by the EzTaxon program. The strain showed the highest similarity to B. cepacia ATCC $25416^{\mathrm{T}}$ (Fig. 1B). The results of the homology analysis confirmed that B. cepacia strain JBK9 exhibited $98.9 \%$ maximal similarity with B. cepacia strain ATCC $25416^{\mathrm{T}}$ and $98.4 \%$ similarity with $B$. pyrrocinia strain LMG $14191^{\mathrm{T}}$; this finding confirmed the isolated strain as a Burkholderia species by comparison against the EzTaxon database.

\section{Antifungal activity of the $\boldsymbol{n}$-hexane-extracted fraction of B. cepacia strain JBK9}

Antifungal activity assay was performed to identify the fraction containing the antifungal compound. The fraction that was soluble in $n$-hexane fraction demonstrated antifungal activity against several tested fungal pathogens. The hexane fraction showed significant activity against $R$. solani, $P$. capsici, and $F$. oxysporum with corresponding growth-inhibitory effects of $58.11 \pm 1.96 \%, 31.27 \pm$ $1.52 \%$, and $59.43 \pm 1.64 \%$ against $R$. solani, P. capsici, and $F$. oxysporum, respectively (Table 2 ). Thus, the above results confirmed the antagonistic activity of $B$. cepacia JBK9 against these fungal pathogens.

\section{Identification of the active antifungal compound}

The antifungal compound isolated from $B$. cepacia strain JBK9 exhibited a characteristic spot on the TLC plate using pyrrolnitrin as a standard (data not shown). Following HPLC analysis of the active fractions yielded a peak with a retention time of $10.5 \mathrm{~min}$ (Fig. $2 \mathrm{~B}$ ), which was in the same as the pyrrolnitrin standard (Fig. 2A). Its antifungal activity against the fungal pathogens was confirmed in a plate assay. This compound had a strong inhibitory effect against $P$. capsici, $F$. oxysporum, and $R$. solani. The ${ }^{1} \mathrm{H}-$ NMR spectrum showed three aromatic protons, two pyrrole protons and an additional broad NH signal (Fig. 2D). And the ${ }^{13} \mathrm{C}$-NMR spectrum revealed the presence of pyrrole $\mathrm{CH}$, aromatic $\mathrm{CH}$, and carbon signals (Fig. 2C). Thus, all the spectroscopic data showed that isolated compound from the strain was pyrrolnitrin.

\section{Motility and root colonization of B. cepacia JBK9}

Several behaviors of Burkholderia species, including swarming and swimming, were examined on solid media containing different concentrations of agar. B. cepacia JBK9 displayed two types of motility, namely swimming (spreading through the semi-soft medium) and swarming (spreading across the surface). B. cepacia JBK9 demonstrated higher swarming and swimming abilities than other Burkholderia strains (Table 3). In contrast, B. cepacia ATCC 25416 and B. pyrrocinia KCTC 2973 were apparently unable to swarm and seemed to lack flagella. We assessed the root colonization capacity of strain JBK9 in red pepper plants after seed treatment in vitro using the double-layer filter method. The results show that the red pepper samples treated with $B$. cepacia JBK9 had a significant root colonization effect compared to the samples treated with other Burkholderia species. As shown in Fig. 3A, the JBK9 treatments had an increase of 26 and $94 \%$ root colonization compared with $B$. pyrrocinia KCTC 2973 and B. cepacia ATCC 25415 treatments, respectively.

\section{Biocontrol ability of $P$. capsici by B. cepacia JBK9}

In all cases, initial bacterial treatment was applied when the red pepper seedlings had been grown for 50 days. The fungal pathogen, $P$. capsici, was applied 3 days later. The bacterial cell suspensions used to treat the plant roots were
Table 1 Antifungal activities of strain JBK9 against various pathogens

\begin{tabular}{lll}
\hline Fungi & Inhibition $(\%)$ & Antifungal activity \\
\hline Phytophthora capsici KACC 40476 & $59.56 \pm 1.52^{\mathrm{a}}$ & ++++ \\
Fusarium oxysporum KACC 40032 & $51.92 \pm 1.64^{\mathrm{b}}$ & ++++ \\
Rhizoctonia solani KACC 40132 & $34.22 \pm 1.96^{\mathrm{c}}$ & ++ \\
\hline
\end{tabular}

Antifungal activity (inhibition zone): - no inhibition zone; + (very weak), $0-5 \mathrm{~mm}$; ++ (weak), > 5-10 mm; +++ (moderate), > 10-15 mm; ++++ (strong), > 15-20 mm; +++++ (very strong), > $20 \mathrm{~mm}$ as the distance between the fungal pathogen and the area of antagonist growth after 7 days. The mean values were calculated from 5 replicates

Values with different alphabetic superscripts in the same column are significantly different $(p \leq 0.05)$ according to Duncan's multiple-range test 

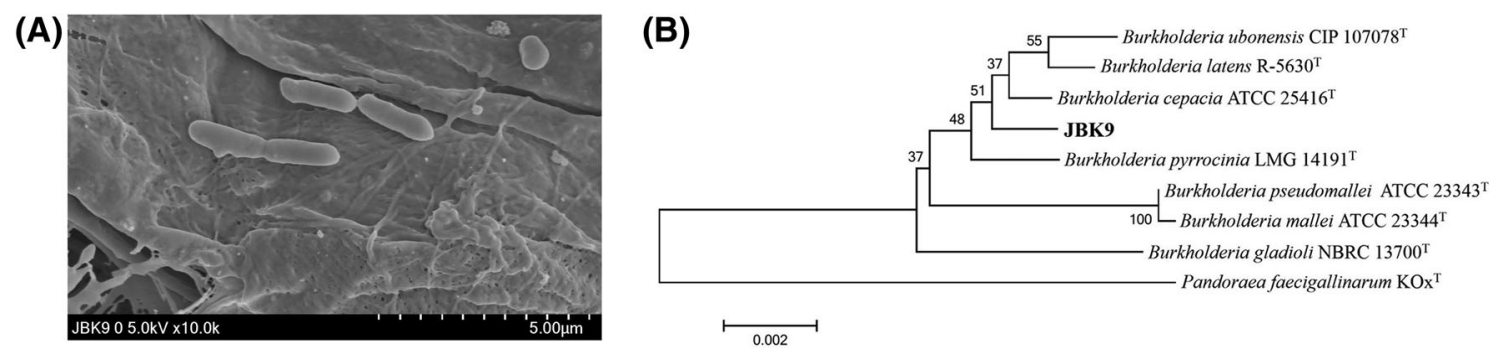

Fig. 1 Features of B. cepacia strain JBK9. (A) Morphology of $B$. cepacia strain JBK9 using scanning electron microscopy. The magnification was $\times 10,000$. (B) A phylogenetic tree showing the genetic relationship between Burkholderia cepacia strain JBK9 and

reference strains based on 16S rRNA sequence analysis. The branching pattern was generated by the neighbor-joining method. The number on each branch indicates the bootstrap values based on 1000 replicates
Table 2 Antifungal activities of $n$-hexane-extracted fraction of $B$. cepacia JBK9 against various pathogens

\begin{tabular}{lll}
\hline Fungi & Inhibition (\%) & Antifungal activity \\
\hline Phytophthora capsici KACC 40476 & $31.27 \pm 1.52^{\mathrm{b}}$ & ++ \\
Fusarium oxysporum KACC 40032 & $59.43 \pm 1.64^{\mathrm{a}}$ & ++++ \\
Rhizoctonia solani KACC 40132 & $58.11 \pm 1.96^{\mathrm{a}}$ & ++++ \\
\hline
\end{tabular}

The result of antifungal activity was expressed as the distance between the fungal pathogen and the area of antagonist growth after 7 days. - no inhibition zone; + (very weak), $0-5 \mathrm{~mm}$; ++ (weak), > 5-10 mm; +++ (moderate),$>10-15 \mathrm{~mm} ;++++$ (strong), $>15-20 \mathrm{~mm} ;+++++$ (very strong), $>20 \mathrm{~mm}$ The mean values were calculated from 5 replicates

Values with different alphabetic superscripts in the same column are significantly different $(p \leq 0.05)$ according to Duncan's multiple-range test
(A)

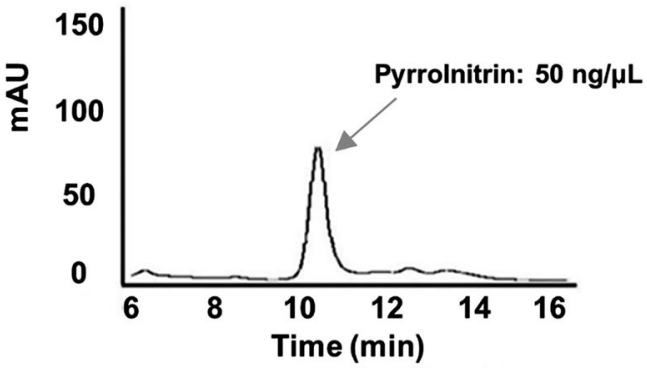

(C)

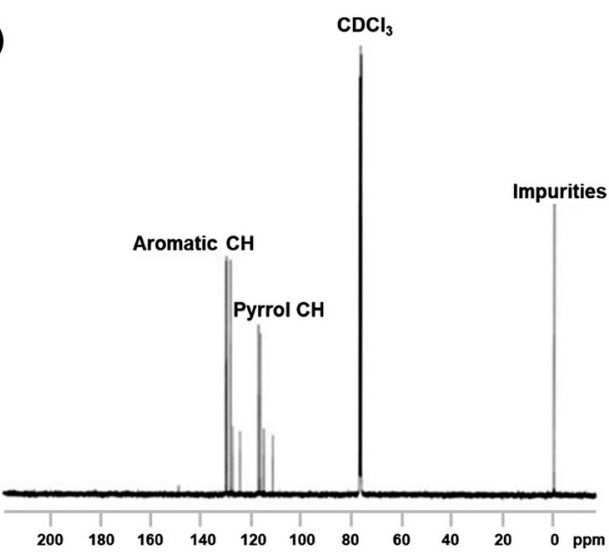

(B)

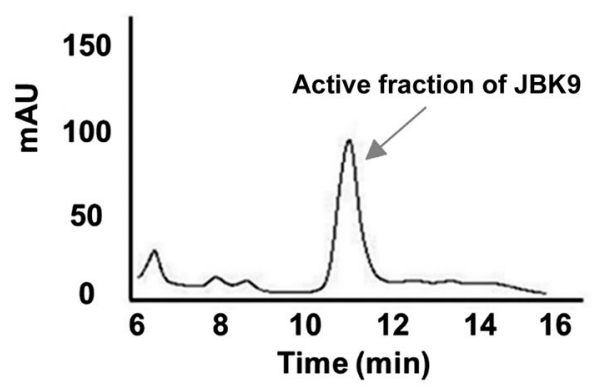

(D)

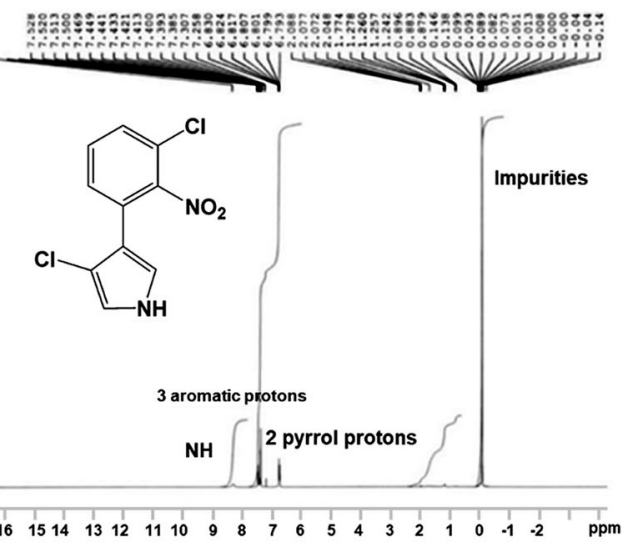

Fig. 2 Identification of pyrrolnitrin from B. cepacia strain JBK9. High-performance liquid chromatography analysis of (A) pyrrolnitrin standard and $(\mathbf{B})$ isolated active fraction from B. cepacia strain JBK9. Active fraction's (C) ${ }^{13} \mathrm{C}-\mathrm{NMR}$ spectrum and (D) ${ }^{1} \mathrm{H}-\mathrm{NMR}$ spectrum 
Table 3 Motility test of Burkholderia species

\begin{tabular}{lll}
\hline Strains & Swarming test & Swimming test \\
\hline B. cepacia JBK9 & +++++ & +++++ \\
B. pyrrocinia KCTC 2973 & - & - \\
B. cepacia ATCC 25416 & - & -
\end{tabular}

The results of swarming and swimming test were expressed as the distance cell moved out from the center of plate. - not detected;,$+>$ $1.5 \mathrm{~cm},<2 \mathrm{~cm} ;++,>2 \mathrm{~cm},<2.5 \mathrm{~cm} ;+++,>2.5 \mathrm{~cm},<3 \mathrm{~cm}$; $++++,>3 \mathrm{~cm},<3.5 \mathrm{~cm} ;+++++,>4 \mathrm{~cm}$

(A)

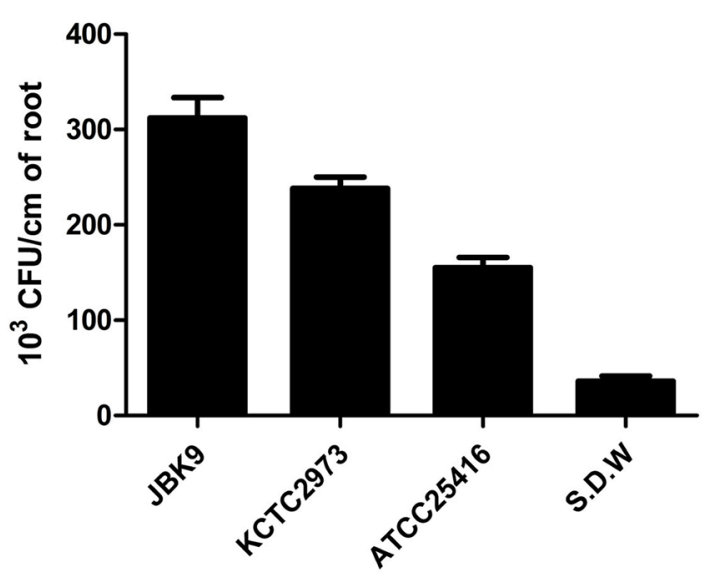

diluted to a final concentration of $10^{7} \mathrm{CFU} / \mathrm{mL}$ before inoculation. The spore concentration of $P$. capsici was determined by hemocytometer counting and adjusted to $10^{5}$ conidia/mL of water. The plant growth was examined after treatment with water only, LB broth only, or $P$. capsici plus the bacterial strains $B$. cepacia JBK9, $B$. pyrrocinia KCTC 2973, and B. cepacia ATCC 25416 or $P$. capsici only (Fig. 3C). The disease control efficacies measured for the above treatment conditions were 100 , 100, 93.2, 92.1, 30.7, and 9.5\%, respectively (Fig. 3B). Therefore, compared with two other Burkholderia species

(B)

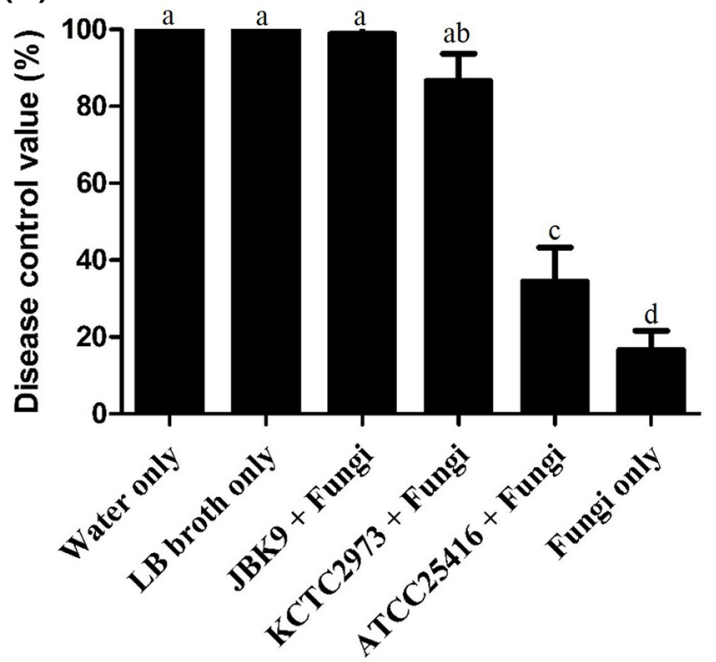

(C)

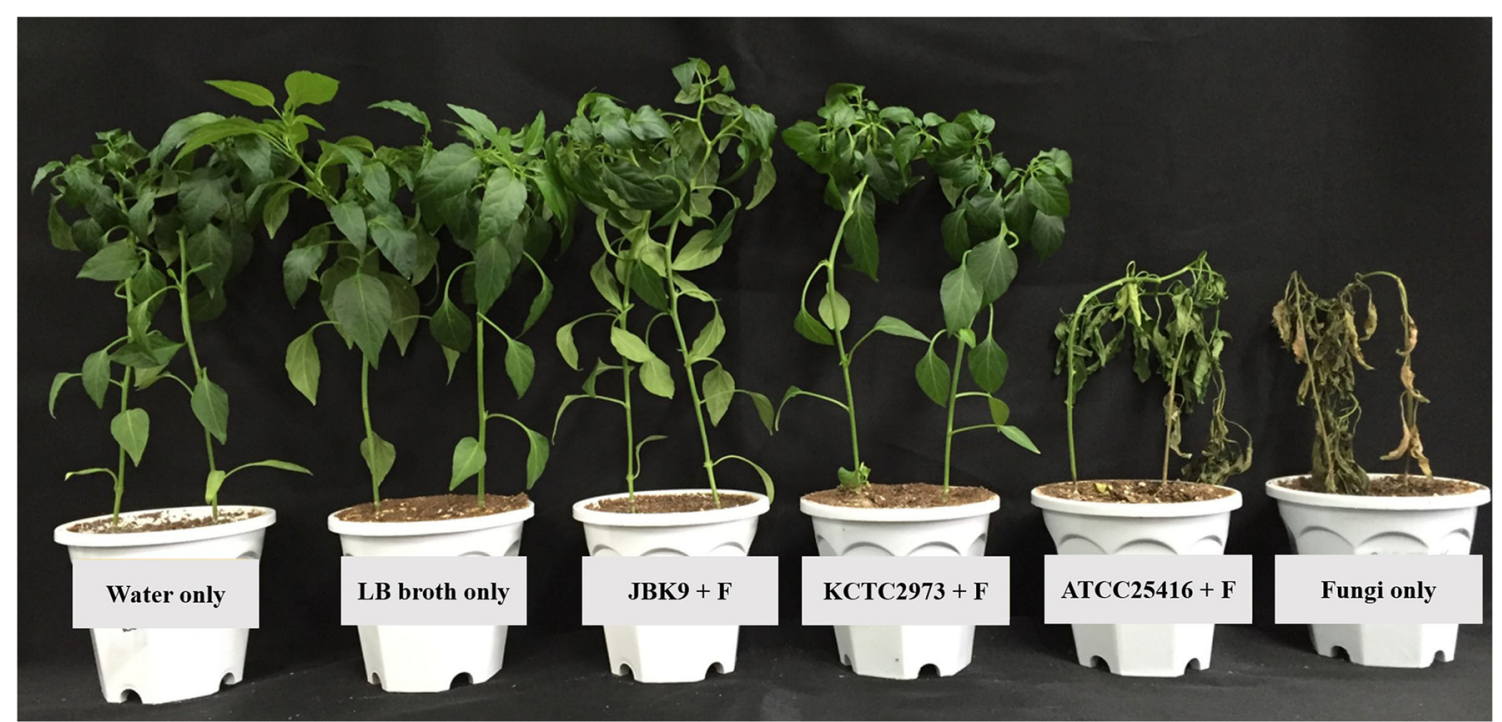

Fig. 3 The plant growth-promoting activity of the B. cepacia strain JBK9. (A) The density of root colonization by Burkholderia species. S.D.W, sterile distilled water. (B) Disease control efficiencies of Burkholderia species. The data represent means from four independent experiments with ten plants per treatment ( \pm SE, $n=$ 40). Different letters in rows show significantly different one-way ANOVA and Duncan's post hoc tests $(p<0.05)$. (C) Biocontrol by Burkholderia species against Phytophthora blight of red pepper plants 
(B. pyrrocinia KCTC 2973 and B. cepacia ATCC 25416), B. cepacia JBK9 showed a stronger antifungal activity against $P$. capsici. Prior to the in vivo pot experiment, we confirmed the antifungal activities of these Burkholderia species using an in vitro dual-culture method. This demonstrated that the antifungal activity of $B$. cepacia JBK9 was higher than that of other Burkholderia species.

\section{Discussion}

In this study, we collected 25 soil samples and isolated a bacterial strain that exhibited antifungal activity using the dual-culture method. The isolated strain showed antifungal activity against $P$. capsici, $F$. oxysporum, and $R$. solani. The isolated strain was named JBK9 and was identified as B. cepacia based on comparison of $16 \mathrm{~S}$ rRNA gene sequence. In recent years, the genus Burkholderia has been phylogenetically well characterized and has been revealed to comprise species that are remarkably functionally diverse [19]. Burkholderia strains are isolated from the rhizosphere of healthy plants and are generally involved in promotion of plant growth and inhibition of plant disease [20]. B. cepacia JBK9 has extensive antifungal activities against plant pathogens. The key mechanism for the antagonistic effects of $B$. cepacia against plant pathogens is the production of secondary metabolites such as pyrrolnitrin [11], cepacin [21], volatile ammonia, and siderophores [22].

The results from HPLC and NMR analyses showed that B. cepacia JBK9 produces the antibiotic pyrrolnitrin, which was first reported from Pseudomonas pyrrocinia [23]. pyrrolnitrin production was also reported by other strains like Pseudomonas aeruginosa, $P$. cepacia, and $P$. fluorescens. And the following studies confirmed the biosynthesis of pyrrolnitrin from tryptophan. Not only the Pseudomonas species, but also the other strains like $M y x$ ococcus fulvus and Enterobacter agglomerans produce pyrrolnitrin [24, 25]. Pyrrolnitrin exhibits broad-spectrum of antimicrobial activities against phytopathogenic fungi as well as pathogenic bacteria.

Bacterial motility is a key factor in their capacity for root colonization. A high motility can confer a high rhizoplane-colonizing ability in terms of movement both from soil to roots and along the roots. The importance of motility for pathogens and useful microorganisms for competitive advantage in rhizosphere soil has been established [26]. An association between the motility and virulence of plant pathogenic bacteria such as Agrobacterium tumefaciens and Pseudomonas syringae pv. tabaci was demonstrated [27]. Beneficial or pathogenic bacteria with a high motility have a high competitiveness and root colonization ability in the rhizosphere. Therefore, flagella-mediated motility has been thought to assist bacteria in finding favorable environments or escaping harmful ones and successfully competing with other organisms. In the present study, the motility of strain JBK9 was found to be better than that of other Burkholderia species.

The potential for biological control of strain JBK9 was evaluated in a pot trial. As shown in Fig. 3C, the disease control efficiency of JBK9 in $P$. capsici-infected red pepper plants was higher than that in the controls and other Burkholderia strains. This result demonstrated that the excellent motility and root colonization of strain JBK9 prevented the zoospore-mediated infection of red pepper plants by the fungal pathogen $P$. capsici. The production of pyrrolnitrin by strain JBK9 may play a key role in inhibiting the mycelial growth of $P$. capsici [28]. This antimicrobial compound might also inhibit or destroy the $P$. capsici zoospores. In conclusion, red pepper plants treated with $B$. cepacia strain JBK9 were significantly protected from plant disease caused by the fungal pathogen $P$. capsici. This bacterial strain can be applied efficiently in the field as a biocontrol agent through agricultural facilities. In our next study, the detailed mechanisms of pyrrolnitrin production and root colonization by strain JBK9 will be studied by a genetic analysis using the nextgeneration sequencing technique.

Acknowledgments This research was supported by the Basic Science Research Program through the National Research Foundation of Korea (NRF), Funded by the Ministry of Education (NRF2015R1D1A1A01057187).

\section{References}

1. Le DT, Vu NT (2017) Progress of loop-mediated isothermal amplification technique in molecular diagnosis of plant disease. Appl Biol Chem 60:169-180

2. Hausbeck MK, Lamour KH (2004) Phytophthora capsici on vegetable crops: research progress and management challenges. Plant Dis 88:1292-1303

3. Gisi U, Cohen Y (1996) Resistance to phenylamide fungicides: a case study with phytophthora infestans involving mating type and race structure. Annu Rev Phytopathol 34:549-572

4. Hallberg GR (1987) Agricultural chemicals in ground water: extent and implications. Am J Altern Agric 2:3-15

5. Kim HS, Sang MK, Jeun YC, Hwang BK, Kim KD (2008) Sequential selection and efficacy of antagonistic rhizobacteria for controlling Phytophthora blight of pepper. Crop Prot 27:436-443

6. Heungens K, Parke J (2001) Postinfection biological control of oomycete pathogens of pea by Burkholderia cepacia AMMDR1. Phytopathology 91:383-391

7. Howell C, Stipanovic R (1979) Control of Rhizoctonia solani on cotton seedlings with Pseudomonas fluorescens and with an antibiotic produced by the bacterium. Phytopathology 69:480-482

8. Baker C, Stavely J, Mock N (1985) Biocontrol of bean rust by Bacillus subtilis under field conditions. Plant Dis 69:770-772

9. Cimermancic P, Medema MH, Claesen J, Kurita K, Brown LCW, Mavrommatis K, Pati A, Godfrey PA, Koehrsen M, Clardy J 
(2014) Insights into secondary metabolism from a global analysis of prokaryotic biosynthetic gene clusters. Cell 158:412-421

10. Jeong Y, Kim J, Kim S, Kang Y, Nagamatsu T, Hwang I (2003) Toxoflavin produced by Burkholderia glumae causing rice grain rot is responsible for inducing bacterial wilt in many field crops. Plant Dis 87:890-895

11. Cartwright DK, Chilton W, Benson D (1995) Pyrrolnitrin and phenazine production by Pseudomonas cepacia, strain $5.5 \mathrm{~B}$, a biocontrol agent of Rhizoctonia solani. Appl Microbiol Biotechnol 43:211-216

12. Reyes-Chilpa R, Jimenez-Estrada M, Estrada-Muñiz E (1997) Antifungal Xanthones from Calophyllum brasiliensis Heartwood. J Chem Ecol 23:1901-1911

13. Mejri L, Hassouna M (2016) Characterization and selection of Lactobacillus plantarum. Appl Biol Chem 59:533-542

14. Chun J, Lee JH, Jung Y, Kim M, Kim S, Kim BK, Lim YW (2007) EzTaxon: a web-based tool for the identification of prokaryotes based on $16 \mathrm{~S}$ ribosomal RNA gene sequences. Int $\mathrm{J}$ Syst Evol Microbiol 57:2259-2261

15. Lee CK, Jang MY, Park HR, Choo GC, Cho HS, Park SB, Oh KC, An JB, Kim BG (2016) Cloning and characterization of xylanase in cellulolytic Bacillus sp. JMY1 isolated from forest soil. Appl Biol Chem 59:415-423

16. Rashid MH, Kornberg A (2000) Inorganic polyphosphate is needed for swimming, swarming, and twitching motilities of Pseudomonas aeruginosa. Proc Natl Acad Sci USA 97:4885-4890

17. Bae Y, Kim H, Park C (1990) An improved method for rapid screening and analysis of root colonizing ability of biocontrol agent. Kor J Plant Pathol 6:325-332

18. Kim KD, Nemec S, Musson G (1997) Control of Phytophthora root and crown rot of bell pepper with composts and soil amendments in the greenhouse. Appl Soil Ecol 5:169-179

19. Coenye T, Vandamme P (2003) Diversity and significance of Burkholderia species occupying diverse ecological niches. Environ Microbiol 5:719-729
20. Gu G, Wang N, Chaney N, Smith L, Lu SE (2009) AmbR1 is a key transcriptional regulator for production of antifungal activity of Burkholderia contaminans strain MS14. FEMS Microbiol Lett 297:54-60

21. Parker WL, Rathnum ML, Seiner V, Trejo WH, Principe PA, Sykes RB (1984) Cepacin A and cepacin B, two new antibiotics produced by Pseudomonas cepacia. J Antibiot 37:431-440

22. Darling P, Chan M, Cox AD, Sokol PA (1998) Siderophore production by cystic fibrosis isolates of Burkholderia cepacia. Infect Immun 66:874-877

23. Arima K, Imanaka H, Kousaka M, Fukuta A, Tamura G (1964) Pyrrolnitrin, a new antibiotic substance, produced by Pseudomonas. Agric Biol Chem 28:575-576

24. Gerth K, Trowitzsch W, Wray V, Höfle G, Irschik H, Reichenbach H (1982) Pyrrolnitrin from Myxococcus fulvus (myxobacterales). J Antibiot 35:1101-1103

25. Chernin L, Brandis A, Ismailov Z, Chet I (1996) Pyrrolnitrin production by an Enterobacter agglomerans strain with a broad spectrum of antagonistic activity towards fungal and bacterial phytopathogens. Curr Microbiol 32:208-212

26. de Weert S, Vermeiren H, Mulders IH, Kuiper I, Hendrickx N, Bloemberg GV, Vanderleyden J, De Mot R, Lugtenberg BJ (2002) Flagella-driven chemotaxis towards exudate components is an important trait for tomato root colonization by Pseudomonas fluorescens. Mol Plant Microbe Interact 15:1173-1180

27. Gomez-Gomez L, Boller T (2002) Flagellin perception: a paradigm for innate immunity. Trends Plant Sci 7:251-256

28. Sopheareth M, Chan S, Naing KW, Lee YS, Hyun HN, Kim YC, Kim KY (2013) Biocontrol of late blight (Phytophthora capsici) disease and growth promotion of pepper by Burkholderia cepacia MPC-7. Plant Pathol J 29:67-76 